\title{
Cross-Functional Maintenance And Logistics Business Process Integration: Lessons From A Large Oil And Gas Company
}

Johannes P van der Westhuizen, Vaal University of Technology (VUT), South Africa Martin West, Hamdan Bin Mohammed Smart University, United Arab Emirates

\begin{abstract}
The purpose of this research focused on integration and alignment of maintenance and logistics functions in a large ERP system in an oil and gas company to demonstrate how cross-functional integration can improve operations. A design science approach has been used based on a case study of a large oil and gas company. The study found that limited cross-functional integration involving the logistics function exists. Proposed process redesign involves activities include improved storage and picking strategies, information exchange, notification of fully received components at the warehouse and an improved shipping strategy. These improvement strategies have been tested through random questionnaires and most respondents support the improvements. This study shows that business process improvement facilitated by cross-functional process integration should realise substantial financial benefits. We have shown that warehouse operation strategies do have an impact on the work order performance through the on-time delivery of its components. In addition, regular communication and utilisation of the available information can also improve the scheduling of work order execution. These benefits are not limited to the company in question but the results show that if companies in general give more attention to cross-functional integration, substantial benefits are possible. The focus of this study is uncommon as it is the integration of logistics and maintenance functions within an organisation. We show substantial process improvements are possible. It therefore provides another opportunity for business process improvement experts to better align various systems and processes.
\end{abstract}

Keywords: Cross-Functional Integration; Business Process; Maintenance; Warehouse

\section{INTRODUCTION AND BACKGROUND}

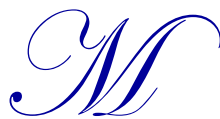

aintenance planning is an integral sequence of activities within many capital-intensive industries but it frequently remains isolated from other critical business functions. While there has been much examination of business process rationalization and cross-functional integration in several business areas, maintenance and logistics integration has been neglected, despite the apparent possibility for significant systemwide improvements. The maintenance function is no longer regarded as a 'second class' function within many businesses (Kutucuoglu et al., 2002). However, it has become increasingly critical that the function can create value and fulfil other stakeholders' expectations (Söderholm et al., 2007)

This study focuses on the integration of maintenance planning and logistics in SAP -ERP system. In particular, we focus on the work order materials delivery process across these two departments. The goal is to study the current work order process to identify areas of improvements at the warehouse operation side and then to suggest an enhanced process to implement these improvements.

The importance of collaboration in cross-functional processes has been stressed in several studies (Berente et al., 2009, Ellinger, 2000, Bititci et al., 2007, Pagell, 2004, Giménez and Ventura, 2003). The logistics processes are no exception to any cross-functional process although not many studies have been published. 
Several relevant studies were reviewed by van Hoek et al. (2008), where the focus was on cross-functional rationalisation of logistics processes. The results showed a great body of research on the integration between logistics and the marketing, sales, and product development processes. None of the other core functions of the enterprises, like HR, IT, and maintenance, were studied in respect to the integration with logistics. Moreover, most of the studies focused on a single process stakeholder view, using surveys as the research methodology.

The dearth of research in this area suggests the research question how can logistics and maintenance processes be integrated and what benefits can be realised? These questions are answered through an in-depth study of work order materials delivery across the logistics and maintenance departments. First, we review relevant literature, before introducing the focal company for the research and outlining the research method that we used. Next, we discuss the key findings from the case study, before discussing these in relation to key literature. Finally, we conclude and discuss the limitations of this research and outline some areas for future research.

\section{LITERATURE REVIEW}

\section{Warehouse Design}

The warehouse design concerns the strategic objectives of the company. It includes the long- and short-term objectives. Gu et al. (2007) listed the five main activities included in the warehouse design, which are Overall Structure, Sizing and Dimensioning, Department Layout, Equipment Selection, and Operation Strategy. Rouwenhorst et al. (2000) also specified that processes, resources, and organizations should be carefully evaluated within the warehouse design. These three axes need to be evaluated at strategic, tactical, and operational levels to ensure optimal warehouse operation performance.

The overall structure is the process of deciding the flow of the materials by identifying the departments included in the operation (like receiving, storing, and shipping) and specifying the relative locations of these departments. The sizing and dimensioning is responsible for defining the warehouse size and each department's dimensions. The department layout focuses on the internal layout and design of the warehouse; for example, how many aisles of certain length and width are required. It also looks into the orientation of aisles and inner and outer door locations. The equipment selection focuses on the decisions of automation enabling, materials handling equipment selection, and storage equipment. The Operation strategy, which can be a long-term design or short-term design, identifies the storage and order-picking strategies to be employed in the warehouse (Gu et al., 2007).

\section{Warehouse Operations}

The warehouse operation is concerned about the management of receiving materials inwards from outside the vendor or other warehouses; then storage of these received items until needed by customers. After receiving a customer order, the order-picking process takes place, followed by dispatch of the picked item for packing and shipping through the shipping department. The two main processes that received most of the research and studies in warehouse operations are the storage processes and the order-picking processes.

\section{Storage}

The Storage process deals with the decision of where to store a received item. It includes a group of rules and strategies that can be used to assign a location within the warehouse to the received item (de Koster et al., 2007). The objectives of the different storage strategies are to optimise the picking activity when the stored item is needed to be picked to fulfil a customer's order or a better utilisation of warehouse space. These different strategies include Random Storage, resulting in efficient space utilization (Petersen, 1999, Hompel and Schmidt, 2007, Petersen and Aase, 2004); Dedicated Storage, requiring more space but improving on utilisation of materials handling equipment (Gu et al., 2007, Larson et al., 1997, Guenov and Raeside, 1992); and Class-based Storage, combining elements of Dedicated and Random Storage to allocate dedicated blocks, whereby random allocation occurs within the block, seeking a tradeoff between the other, pure, strategies (Larson et al., 1997) 


\section{Order Picking}

The order-picking process is the most costly process in the warehouse operation (Tompkins et al., 2003) because it requires either intensive labour activities or huge investment in automation equipment (de Koster et al., 2007). Therefore, many studies have been conducted in order to optimise the picking process. However, this process is affected by other strategies and decisions in the warehouse operation, such as the storage strategy, the warehouse layout, and the selected picking system.

The order-picking process consists mainly of picking, batching, routing, and sorting activities. There are different strategies to execute these activities based on several factors, like the level of automation and the warehouse layout and configuration. Rim and Park (2008) define these activities as the execution stage of the picking process, and they defined the planning stage as the selection of orders to fulfil during an operation cycle.

\section{Batching}

Batching is the function of grouping or splitting orders into batches and submitting them for the picking process (Guenov and Raeside 1992). For better labour efficiency, it is recommended to handle small orders together. This efficiency is realised by allowing the picker to simultaneously pick more items in a single trip, a so-called picking wave. The distance travelled by the picker to pick a group of orders in one trip is shorter than the distance of picking each item separately (Gibson and Sharp 1992).

When a batch picking is employed, a sorting process must integrate each order's items (Rouwenhorst et al., 2000). Studies have shown that batching can produce significant savings in picking time of small orders (Petersen and Aase, 2004); however, if order volumes are low, batching incurs additional costs due to order preparation and transport of items (Hompel and Schmidt, 2007)

\section{Routing}

Order-picking performance is also affected by the determination of the path a picker should follow to complete a picking trip or wave - the routing strategy. The route is selected to minimise the distance travel, thus reducing the picking process cost (Petersen, 1999).

Heuristics are widely used in warehouse operation as they are easier to implement and their consistency reduces the picker confusion and errors (Petersen and Schmenner, 1999, Petersen, 1999). The most commonly used are the SShape strategy (it also called traversal strategy); the return strategy; the mid-point strategy; the largest gap strategy; and the combined strategy, which uses elements of the S-shape and return strategies (Petersen, 1997).

\section{Work Order and Materials Management}

It is clear that the work orders involve interfaces with several departments within an organisation (Figure 1). A crucial interface is with the materials management processes. To provide better control over company assets and inventory, many organisations assign the materials management activities to a different department other than the maintenance department. This interface requires continual communication between maintenance and material management. However, it receives less attention from management, and it offers a significant area of improvements (Palmer, 1999).

The interface occurs during the planning and scheduling stages of the work order lifecycle. During the planning process, the planner identifies the parts needed to carry out a specific job. If these parts are available in the company's on-hand inventory, they will be reserved; if they are not available they will be ordered from suppliers. The reservation is the process of allocating on-hand inventory of a specific item to the work order. This ensures that the items needed for a work order are available when the execution stage starts. During the scheduling stage, the planner sets a schedule of what materials need to be delivered to the workshop and when (Palmer, 1999). 
Figure 1. Work order and MRO cost relationship. Based on Figure I-4 (Wireman, 2008, p. xii).

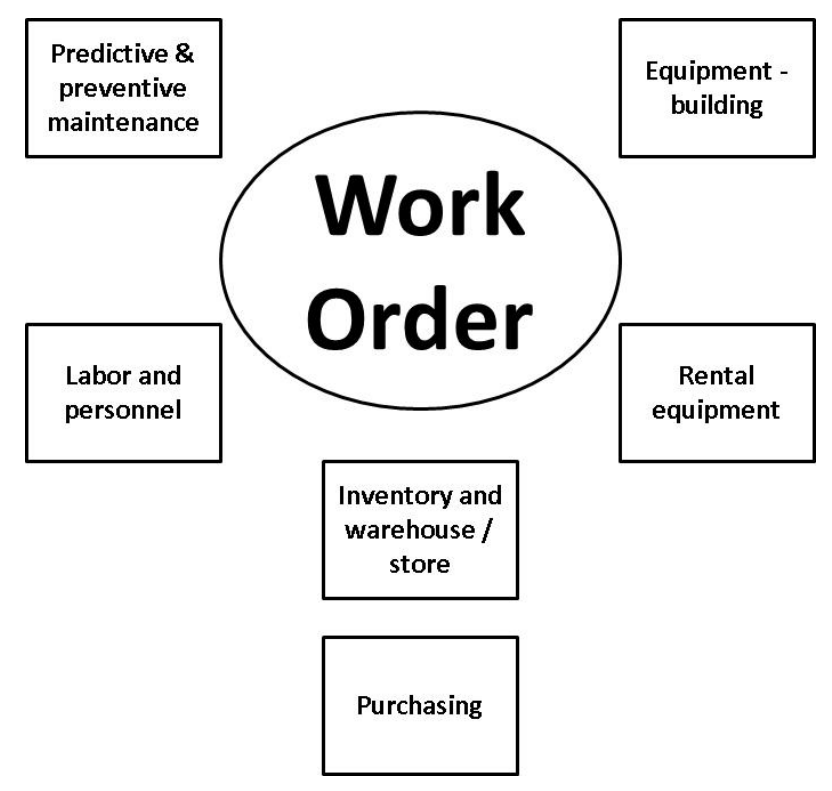

\section{Interdepartmental Integration}

Interdepartmental integration is required when there is a business process that is executed across several department boundaries. Interdepartmental integration is the joining of several departments within an organisation to perform a function that share part of its process. A department receives an input and then processes it to add value to it. After that the output will be passed to the next department in the chain for further processing (Berente et al., 2009).

Usually, the performance of this function is affected by how well these departments communicate and support each other throughout the process. To get the best outcome from an interdepartmental integration, departments must collaborate toward achieving a common goal or predefined objectives. The communication must often be richer than can be achieved through regular communications like faxes, meetings, and emails. However, cooperation and willingness to support staff in the involved department is also required (Ellinger, 2000). Therefore, with collaboration, information and resources are shared, assets are efficiently utilised, and knowledge and skills are improved (Bititci et al., 2007).

Such integration can be internal or external. The internal integration is the integration of several departments of a single organization; external integration is the integration of an organisation with other organisations (Pagell, 2004). If an organisation is seeking a development of efficient external integration, then an efficient internal integration is believed to be required (Giménez and Ventura, 2003). Gimenez and Ventura (2005), in their study of the impact of logistics integration on performance, concluded that companies appreciate the importance of the internal integration and collaboration to the success of their external integrations.

As business processes become increasingly computerized, e-maintenance systems will become critical to effective and efficient operations (Márquez et al., 2009). This may aid the integration of maintenance functions with upstream functions, improving overall performance (Mahmood et al., 2011).

Van Hoek et al. (2008) reviewed a large body of literature and found that two-thirds of the logistics integration papers focused on the integration between logistics and marketing or sales. The remainder investigated the logistics integration with research and development $(\mathrm{R} \& \mathrm{D})$ or production. None focused on the logistics integration with the other departments within organisations. This is very understandable as traditionally logistics functions were part of the marketing and production departments (Gimenez and Ventura, 2005). 
Even though interdepartmental integration is very important and it improves process performance, many of the operational cross-functions involve logistics activities are unexplored (van Hoek et al., 2008). Maintenance is one of these operational functions that remain unexplored.

\section{RESEARCH METHOD \& DESIGN}

\section{Research Question}

After reviewing the literature on the warehouse operation strategies and processes, maintenance work order cycles, and interdepartmental integration, it is clear that the integration between warehouse logistics operations and maintenance planning has not received substantial attention. It was also indicated in the literature that the maintenance and warehouse operation interface largely involves inventory and work order components staging processes (Palmer, 1999, Wireman, 2008). This consists of storing, picking, and delivering the work order components. While maintenance planners attempt to ensure the availability of all needed components before scheduling work order execution, to avoid operation disruption, they are challenged with the use of the Just-in-Time and other management approaches and technologies used in warehouse operations to reduce inventory (Marquez and Gupta, 2006). The ontime availability of the materials and spare parts required for a maintenance job is a key element to its success (Garg and Deshmukh, 2006). Therefore, by improving the storing and picking processes, which are major components of the cost and performance of order fulfilment, the on-time delivery of the work order components can be improved (Petersen and Aase, 2004).

This research therefore tries to answer the following question: "How can work order components of storage, picking, and delivery processes be improved to better serve the conflicted needs of maintenance and warehouse logistics operations?" The objective of this research is to analyse the work order components storing and picking processes, taking into consideration the viewpoints of the warehouse operation and the maintenance planning personnel, in order to resolve the conflict in their needs through the improvements of these processes.

To support this process improvement three questions have been formulated. First, what is the best storing strategy to supporting this process improvement? This focuses on identifying the best possible way of storing work order components after receiving them. Several strategies were proposed in related literature (de Koster et al., 2007, Petersen, 1999, Hompel and Schmidt, 2007, Petersen and Aase, 2004, Gu et al., 2007, Larson et al., 1997). Throughout the analysis of the storing process, one of these strategies is selected.

Second, how should the picking be conducted to support this process? This focuses on how the picking process should take place when the work order is executed. The current picking process will be studied to define areas of improvements, and then enhancement will be suggested.

Third, what information that can be shared across departments to improve this process? This focuses on the available information within the SAP system will be identified. After that, information that can be shared among departments to enhance process performance will be evaluated.

\section{Research Method}

Logistics problems are messy and ill-structured, which is the nature of most of the business problems in real-world situations (Näslund, 2002). Logistics functions and operations tend to be largely cross-functional. Therefore, this research uses empirical interpretive research methods by applying a design science research approach. Craighead et al. (2007) believe that logistics studies should use multiple research approaches, which result in better findings and promote synergies produced from the combination of the methods used. The combination of approaches will help to (1) enrich the development of the conceptual model; and in (2) using triangulation to enhance the interpretation of the finding (Gable, 1994).

Part of the research involves the search and creation of a new process design, or artefact, and so it falls under the design science research paradigm. While there have been multiple approaches proposed to guide design science research projects (Walls et al., 1992, Venable, 2006); the approach suggested by Vaishnavi and Kuechler (2004) was 
adopted as it is a relatively succinct, clear, and integrative approach. It provides coherent and easily followed steps that match those needed to complete the research.

This research paradigm is inherited from problem-solving approaches, in which the researcher uses imagination and empirical facts to invent the desired situation (Laurel, 2003). Although design research has a foundation in problem solving, Hevner et al. (2004) stressed that design research should address a specific problem class or type. Within a problem class, several stakeholders' views are considered in the solution. This differs from a normal problem-solving approach where a specific problem with a single stakeholder view is solved. Hevner et al. (2004) went further to identify the features of the problems that can be studied using design research:

- Unstable requirement with poorly-defined constraints.

- The components of the problem have very complex solutions and interactions.

- The design process is fixable and can adapt to any defined model.

- The developed solution is highly dependent on researcher creativity.

- The successful solution is highly dependent on the synergy resulting from effective teamwork.

Using these criteria to evaluate the appropriateness of the design science approach to our research project, we judge it to be suitable as:

- The problem has complex solutions addressing several strategies in warehouse management and interactions between two business functions within the company

- The design process will generate an enhanced business process which can be design using any process improvements approach

- The developed solution is highly dependent on researcher creativity

- The successful solution is highly dependent on the synergy resulting from effective teamwork. The objective of this research is to promote the collaboration between warehouse management and maintenance, which will require effective teamwork to success.

The focuses on the system development which can lead to theoretical contributions (Venable, 2006). However the focus is on the process of creation of an artefact. In design research, the researcher invents a new solution (Venable, 2006). This new solution eliminates facets of the current reality to achieve a desirable future state (Hevner et al., 2004). Vaishnavi and Kuechler's (2004) general methodology for design research consists of five steps: awareness of the problem, suggestions for improvement, development of enhanced processes, evaluations, and articulation of a conclusion. The current study follows these steps.

\section{Awareness Step}

The current state with no integration of processes between maintenance and logistics operations has been identified as a source of concern and frustration for workers.

\section{Suggestion Step}

In the suggestion step, the research team envisions a creative solution to or modification of the existing components of the situation to overcome the identified problems. This step does not propose a complete solution to the problems; the focus is instead on highlighting the major components of the solution (Vaishnavi and Kuechler, 2004) In this research, the required improvements to overcome the gaps identified in the previous step were be highlighted.

\section{Development Step}

In the development step, the suggestions proposed are to be implemented in an artefact. Depending on the situation studied, the development of the artefact could be a new model, process, method, or system (March and Smith, 1995). 
This research developed an enhanced process to handle the work order materials storage, picking, and delivery. The enhanced process incorporated the required improvements proposed in the suggestion process. The process will be explained in detail and the expected improvements will be highlighted.

\section{Evaluation Step}

The evaluation step involves examination of the developed artefact to ascertain whether it actually overcomes the problem identified during the first, Awareness of Problem, step. Quantitative or qualitative measurements can be used to study the behaviour of the new artefact. Therefore, this step analyses the hypotheses made to study the new artefact (Vaishnavi and Kuechler, 2004).

An evaluation model was developed to assess the validity of the suggested artefact in the previous step. A survey was be used to conduct the evaluation test. The sampling method was not random, as the target population is from specific fields with limited numbers of workers. Instead, all relevant workers within the maintenance planning and warehouse logistics operations were surveyed.

This evaluation step in this research was not a final, summative, evaluation of the finished artefact (or finished and implemented business processes); it was a formative evaluation. This is type of formative evaluation is identified by Venable et al. (2012) as a type of evaluation in design science research which is intended to identify areas where the artefact can be improved and modified further.

\section{Conclusion Step}

For any typical research, the conclusion is the last step of the process. At this step, all facts and lessons learned from conducting the research are discussed. It shows the results of the developed artefact and addresses the areas for future research. Limitation of the current research is also discussed in this step.

\section{DATA COLLECTION \& ANALYSIS}

\section{Data Sources}

The data were collected from a single company in Saudi Arabia. The company explores, produces, and refines oil across the Kingdom of Saudi Arabia. An internal supply chain organisation provides the company's departments with procurements, logistics, and warehousing services. The maintenance department is one of the internal customers of the supply chain organisation.

\section{Data Collection Process}

Interviews and surveys were the two main methods were used to collect data during this research. Interviews were conducted with maintenance planners and warehouse operation personnel who use the SAP system to carry out the activities of maintenance work order planning and materials delivery. The purpose of the interviews was to develop an understanding of the current process of storing, staging, picking, and delivering the work order materials. The gaps of the current process were discussed during these interviews. The output of this step was a written detailed discussion of the current process, the current process flowchart, and the gap identification.

Later, surveys were conducted as part of the evaluation phase of the project, to cover a broad base of process users, to help evaluate the effectiveness of the proposed artefacts.

\section{The Interview Method}

The interview is the approach used by a researcher to obtain the interviewees' interpretations, experience, and understanding of their work and living environments (Rubin and Rubin, 2005). Interviews were used to gain insight knowledge about the current process of handling work order components. They were also used to discuss the existing 
problems within the current process and identify the possible ways to overcome them. Therefore, the outcome of these interviews will be used to develop a conceptual model, which will be used to generate the questionnaire afterward. Interviews have particular methodological strengths and weaknesses (Yin, 2009). The strengths of the interview method include:

- Clear insights into a situation can be obtained from an experienced respondent

- Respondents can provide researcher with the situation history

- The interviewer has the chance to clarify questions, hence collecting useful responses

And the weaknesses of this method include:

- High cost and extensive time required

- Poor questions might generate bias in the responses

- Potential loss of data accuracy because of poor recall

- Bias in response because interviewee might provide what the interviewer likes to hear

It was appropriate to use interviews within this research, as the respondents were required to provide in-depth details about the current process of handling work order components and highlight the problems within the current process.

\section{Survey Method}

Surveys can be a qualitative technique, used to capture an understanding of the phenomenon at a point in time (Galliers, 1991). Within this approach, the researchers "sample many respondents who answer the same questions, measure many variables, test multiple hypotheses, and infer temporal order from questions about past behaviour, experiences, or characteristics [...] An association among variables is measured with statistical techniques" (Neuman, 2006, p. 276). Surveys are an accepted tool to study society and organisations (Galliers, 1991). As this research involves research in an organisation, the survey is considered to be a useful tool.

The survey method has particular strengths, including (Galliers, 1991):

- Greater number of variables can be studied

- Large sample sizes reduce the concerns about generalization.

The weaknesses of surveys include (Galliers 1991):

- Little insight is gained about the subject being studied

- Potential for a respondent's bias

\section{ANALYSIS AND OUTCOMES}

This section outlines how the data were analysed to present opportunities for improvement and focuses on the use of the gap methodology, indicating where the present processes fail to achieve the desired outcomes.

\section{Gaps in the Current Process}

The current process of handling the storage and picking of the maintenance work order components has several gaps that can be improved. These gaps affecting the delivery performance and at the same time increase the warehouse operation costs.

The first gap is the double handling of the staging process at two locations within the process. The warehouse operation at the materials management department stages all the work order components until the planner requests it. As each component has a single picking document, the work order components will not be sorted together. Thus, each item is delivered separately. Therefore, the maintenance department must sort and consolidate work order components 
together after receipt. Moreover, work orders might be delivered to the maintenance site partially. Therefore, items received need to be stored again until all the components are available so that a complete task can be completed. The lack of batching and consolidation of work order components during the picking process creates this inefficient use of resources.

The second gap in the process is the lack of collaboration and the use of the available information. Even though all the information about the staged materials is available in the SAP system, the maintenance planner does not use this information to develop the weekly workshop schedule table. Instead, the materials will be requested from the warehouse in patches. Then, when all the components are available at the maintenance site, the schedule will be developed. This approach disregards the opportunities for collaboration with the warehouse operation from the use of available information. Moreover, the weekly workshop schedule table is not shared with the warehouse operation personnel, who are then unable to anticipate the forthcoming workload. The planning and utilisation of the resources at the warehouse operation become suboptimal. However, warehouse operations might be challenged with a huge number of requests for work order components delivery. The performance of these deliveries might be poorer if advanced planning by sharing information between maintenance planning and warehouse operation was instituted.

The third gap is the inefficient warehouse operation. The two main processes of warehouse operation that have a direct impact on the performance of the work order components delivery are the storage process and the picking process.

The storage process does not utilise the available information in the system to optimise the selection of the storage location. During the storing process, the storekeeper does not have information about the work order components stored previously within the staging area. The receiving documents contain the work order reference number, but they do not suggest an optimal storage location for the received item. The SAP system does not have a standard strategy to store the received items based on a reference to a work order.

The storage process uses the simplest storage strategy, which is the Random Storage strategy. Although this strategy provides the best space utilisation of the storage location (Hompel and Schmidt, 2007, Petersen and Aase, 2004), it impacts on the cost of the picking process by generating less efficient picking routes. These routes have a longer travel distance as items to be picked are distributed among the storage locations.

In addition to the long picking routes generated, the picking process does not account for the integrity of the work order components. The system does not generate a consolidated picking list by work order; for example, a work order containing 70 components will have 70 picking documents. All documents are printed in several copies, which contribute to the overall cost of the process. Each picked item must be packed separately as there is no consolidated list. Thus, extra costs are incurred for the additional packing materials, labelling, and processing time. Similar to the storage strategies, the SAP implementation does not have a standard picking strategy to pick items by work order reference.

\section{Suggested Improvements}

From the three gaps discussed earlier in this section and from the interviews conducted with maintenance planners and warehouse operation personnel, the two stakeholders of the process, the following improvements are suggested:

- Eliminate the double handling of the staging process.

- Ensure the utilisation of all the available information to promote the collaboration between the maintenance planning and warehouse operation.

- Adapt a storage strategy that uses the work order as a reference for selecting the storage location at the staging area.

- Ensure the integrity of the work order components during the picking and packing processes.

These improvements can be developed based on three factors, which are order consolidation, regular communication, and scheduled deliveries. The new process tries to eliminate the gaps identified in the previous section, which are double handling activities, lack of collaboration, and inefficient warehouse operation. 


\section{Order Consolidation}

The order consolidation is the process of collecting all the work order components together before shipping it to the workshop. Currently, order consolidation more regularly occurs during the fulfilment of sales orders. Within the warehouse operation, the two processes of storage and picking are the main factors influencing the performance of the order consolidation. To improve the order consolidation, the proposed process ensures the utilisation of all the available information to better perform these two processes.

The storage process starts when an item is received at the staging area. Referring to the database, the system checks whether any item of the work order components has been stored previously. If an item is located, the system proposes that the newly received item is stored in the same location; otherwise, the system proposes the next available location within the storage area. This approach of assigning a storage location uses a dynamic version of the dedicated storage strategy. The system proposes a dedicated location every time a work order component is received. Even though this strategy requires more storage spaces, it usually trades off the storage space against minimising the picker's travel distance (Larson et al., 1997).

Because all the work order components are stored in one location or in locations near each other, the order-picking and sorting will be more efficient. The current process disregards the integrity of the work order components and prints picking documents for each single item in the components' list, which means each item will be packed and shipped separately to the maintenance site. To ensure integrity of work order components, the new process combines all the picking documents into one pick-list containing all the components of the work order to be picked. By assigning a single picking document to a picker, the work order integrity is preserved and the efficiency of the picking process increases. Moreover, fewer documents are printed, which contributes to the reduction of the overall process cost.

Following this, all work order components will be packed together as the sorting has been conducted during the picking process. This approach of combining the work order component into one handling unit is difficult to achieve with the current process, because each item is requested separately and the information is split into several documents, which requires a lot of efforts by the pickers to combine the items after picking.

Using this storage and picking process, each work order will have a consolidated shipment of components, ensuring more efficient warehouse operation. At the same time, it reduces the need for consolidating the components at the maintenance site, which will promote collaboration and a reduction of the double handling efforts.

\section{Regular Communication}

In the current process, both departments, maintenance and warehouse operation, do not share critical information such as completely staged work orders or weekly workshop schedules. In the proposed process, the system will ensure proper communication of this information.

After the storing process, the system checks whether all the work order components are physically received at the warehouse staging area and then sends a notification message to the planner who created the work order. In the current process, the planner needs to check this information manually by going to each work order component view. This process is time-consuming and inefficient. When the planner receives the notification messages about all the completely staged work orders, work starts on the development of the weekly workshop schedule based on relevant information.

When the planner completes the weekly workshop schedule, a notification message containing the scheduled work orders is sent by the system to the warehouse operation. The communication of this schedule helps the warehouse operation to align the available resources to handle the anticipated workload, which will reduce the overall process cost through better planning.

Regular communication of this critical information between maintenance and warehouse operation promotes the teamwork spirit and improves collaboration. It also contributes to the elimination of the double handling of the staging process at two different locations; the maintenance planner has accurate information about the available work order 
ready for scheduling, and at the same time warehouse operation has advanced notification of the upcoming activities. Moreover, with the better utilisation of resources based on information sharing, the robustness of the delivery process is substantially improved, which is one of the reasons behind the need for a second storing location near the workshop.

\section{Scheduled Deliveries}

The scheduled deliveries of work order components ensure a continuous availability of the needed resources to execute the work orders. As discussed in the previous section, the information shared between maintenance planning and warehouse operation enables the scheduled deliveries based on the weekly workshop schedule. This allows shipments to be delivered directly to the workshop, which shorten the delivery process. It also sets a common goal to be achieved by the two departments. Therefore, the collaboration between the departments is promoted, and performance and efficiency are improved.

\section{Evaluation and Validation}

Following the analysis six changes are suggested to improve the delivery process performance:

- The use of a dedicated storage strategy to stage work order components.

- The use of a consolidated pick list containing all the work order components.

- The use of a consolidated packing to pack all the work order components together.

- All the work order components quantities are shipped simultaneously.

- The use of a scheduled deliveries to the workshop based on the weekly workshop schedule.

The sharing of available information. As soon as all the work order components are stored in the warehouse, a notification message is sent to the maintenance planner. The process also suggests that the warehouse operator receives an advanced notice of the workshops schedule.

Following the design research approach of Vaishnavi and Kuechler (2004) these proposed changes were evaluated through a structured process. This was planned to commence with a low-cost survey to evaluate opinions about the proposed changes, before a more substantial pilot study would be undertaken later.

The survey contained seven questions for evaluation using a three-point scale (Agree, Disagree, Neutral). The target population was the company's maintenance planners, workshop schedulers, maintenance engineers, warehouse supervisors, and warehouse specialists. This represents more than 2,500 employees. The survey was sent to a random sample of 200 participants representing the target population. Participants worked in different maintenance departments supporting several types of plants, such as gas plants, oil refineries, marine terminals, and oil pump stations. These are employees who would be directly affected by the implementation of the suggestions and as such would provide a realistic view of the validity applicability of the suggestions. A total of 62 responses were received, which represent $31 \%$ response rate. The responses were then combined under three categories Agree, Disagree, and Neutral. Using a descriptive statistic, the responses under each category were analysed. The results are shown in the table below.

The table shows that the overwhelming majority of the respondents are of the view that the suggested improvements would either be beneficial or they are neutral. In particular, the first five suggestions more than half of the respondents are in favour of the change. The suggestions for sharing and using the weekly workshop schedule to plan and dispatch delivery trips did not receive a significant positive response. On the other hand, almost the same number of respondents had a neutral view, indicating that they were ambivalent about the impact the suggestions might have on enhancing the delivery process. Overall a relatively small percentage of respondents disagree with the proposed improvements. 
Table 1. Summary of survey response frequencies

\begin{tabular}{|c|c|c|c|c|}
\hline No. & Factor & Agreed & Neutral & Disagreed \\
\hline 1 & $\begin{array}{l}\text { Notification of fully received components at the } \\
\text { warehouse }\end{array}$ & $87 \%$ & $5 \%$ & $8 \%$ \\
\hline 2 & $\begin{array}{l}\text { Storage Strategy - dedicated storage based on the } \\
\text { work order reference number }\end{array}$ & $80 \%$ & $12 \%$ & $8 \%$ \\
\hline 3 & Picking Strategy - Pick and sort work order & $77 \%$ & $18 \%$ & $5 \%$ \\
\hline 4 & $\begin{array}{l}\text { Order Completeness - ship all quantities requested } \\
\text { together }\end{array}$ & $66 \%$ & $15 \%$ & $19 \%$ \\
\hline 5 & $\begin{array}{l}\text { Consolidate all work order components in one } \\
\text { package }\end{array}$ & $61 \%$ & $25 \%$ & $15 \%$ \\
\hline 6 & $\begin{array}{l}\text { Scheduled deliveries based on the weekly } \\
\text { workshop schedule }\end{array}$ & $47 \%$ & $39 \%$ & $14 \%$ \\
\hline 7 & $\begin{array}{l}\text { Sharing weekly workshop schedule with } \\
\text { warehouse operation }\end{array}$ & $42 \%$ & $40 \%$ & $18 \%$ \\
\hline
\end{tabular}

The proposed process suggests that information about the complete received work order components at the warehouse can be shared with the maintenance planners. The maintenance planner will then use this information to schedule the work order execution. This suggestion received the highest agreement percentage from the respondents at $87 \%$. Sharing this information among the two departments, Maintenance and Warehouse operation, will improve the internal integration within the company. This integration is believed to be a requirement for the development of efficient external integration (Gimenez and Ventura 2003).

The other information suggested to be shared in the new process is the weekly workshop schedule. This information will be sent to the warehouse operation in advance to be able to plan resources and to be able to anticipate future workloads. Only $42 \%$ of the respondents agreed that sharing this information with the warehouse operation will positively improve the delivery process. This is the lowest percentage received in this survey; however, $40 \%$ of the respondents did not see any effect of this information on the process performance. In addition, the proposed process suggests the use of the weekly workshop schedule to plan the delivery trip. Only $47 \%$ of the respondents agreed that dispatching delivery trips based on the weekly workshop schedule will improve the delivery process performance. On the other hand, $39 \%$ of respondents did not see any effect of this suggestion on the process performance.

As stated in the literature review chapter, the area of integration between maintenance and logistics is still unexplored (van Hoek, Ellinger, and Jonson 2008). This research studied the possible opportunities in this area. By studying the interface between maintenance planning and one part of the logistics functions, which is warehouse operation, many opportunities are addressed to improve collaboration between maintenance planning and logistics. Using the available information in the SAP system, both warehouse strategies and maintenance planning processes can be optimized. The suggested process in this research ensures the utilisation of the available information to enhance the cross-departmental functions and improve the resource utilization.

Three of the suggestions proposed in the new process are believed to have an effect on improving the performance of the work order components delivery process, based on the survey conducted in this study. These suggestions are:

- A notification message sent to the maintenance planner once all the work order components are completely received at the warehouse

- The work order components are staged in one location

- The system generates a consolidated pick list by work order.

\section{Future Cycles of the Design Science Approach}

Further cycles of the design science approach were not undertaken due to time constraints. Based on the feedback from the survey, a pilot study would be undertaken with the most promising of the proposed processes, with rigorous assessment of outcomes of the designed processes. Comparisons with extant processes would then determine which of the processes should be implemented in a full redesign of the maintenance and warehouse operation processes. 


\section{Managerial Implications}

This study shows that business process improvements can be made by focusing on cross-functional process integration. Not only is business process improvement facilitated by cross-functional process integration but if this is done appropriately then substantial financial savings can be realised. We have shown that warehouse operation strategies do have an impact on the work order performance through the on-time delivery of its components. In addition, regular communication and utilisation of the available information can also improve the scheduling of work order execution.

To improve warehouse operations careful consideration should be given to storage strategies. There are various possible storage strategies including random storage strategy, dedicated storage strategy and class-based storage strategy. The proposed process suggests the use of a dynamic version of the dedicated storage strategy. When the first item of a work order components received at the warehouse, the system suggests a storage location based on the work order reference number. This location then will be dedicated to stage the components of that work order only. This approach can serve the goal of the suggested process of storing all the work order components in one storage location.

Even though this approach might require more storage space inside the warehouse, it will substantially reduce the time needed to pick the components during the picking process; hence improving the overall process delivery performance. It is therefore recommended that a dynamic dedicated storage strategy be used to maintenance function within a warehouse environment.

The study also shows that careful consideration should be given to the picking process. Organisations should refrain from piecemeal picking but rather ensure that all the work order components are picked and sorted together before the shipping. This can be achieved by printing a single pick list for all the work order components. Picking all the components in one picking route shorten the distance travelled by the picker, hence, improve the picking process efficiency. Importantly, picking all the work order components together also preserves the integrity of the order. Moreover, the use of pick-and-sort sorting strategy during the picking process eliminates the need for the sorting process afterward. As all the items are stored together in one storage location, the picking and sorting process will require less effort from the storekeeper. The study also confirms that sharing of relevant information in a timely manner would improve the process.

The proposed process suggests that information about the complete received work order components at the warehouse should be shared with the maintenance planners. The maintenance planner will then use this information to schedule the work order execution. Sharing this information among the two departments, Maintenance and Warehouse operation, will improve the internal integration within the company.

The other information suggested to be shared in the new process is the weekly workshop schedule. This information could be sent to the warehouse operation in advance to enable planning of resource utilisation and anticipate future workloads. Combining these various initiatives should ensure a more efficient use of resources and result in real financial savings to a company.

\section{Academic Implications}

This study sheds light on the challenges involved in the integration of maintenance and logistics functions. It is clear that there is a great deal of complexity surrounding the activities within these functions. The research indicates to logistics researchers that the design science approach can provide significant benefits in terms of providing a structured method to analyse and improve existing operations. The results also indicate that not all communication would be considered equally valuable; notification of complete orders was considered vital by most respondents, but the sharing of a weekly workshop schedule was not considered to be useful. These results are based on a survey and so there may be some misunderstanding on the parts of the respondents, or it may show that the information that is considered valuable is information in 'chunks', which require no interpretation or analysis, such as a 'notification'; a shared schedule would require interpretation and comparison with existing work. The implication is that cross-functional process design must manage the more mundane analysis and interpretation elements, and instead focus on clear communication of information to users. 


\section{CONCLUSIONS}

Process improvement through cross-functional process integration is often overlooked as a way of improving efficiency within an organisation. As shown in the literature review, the area of integration between maintenance and logistics is still substantially unexplored (van Hoek et al., 2008). By studying the interface between maintenance planning and one part of the logistics functions, which include warehouse operations, a number of opportunities have been identified to improve collaboration between maintenance planning and logistics. Using the available information in the SAP system, both warehouse strategies and maintenance planning processes can be optimized. The suggested process in this research ensures the utilisation of the available information to enhance the cross-departmental functions and improve the resource utilization.

\section{Limitations}

This research is conducted using a single case. Generalisations to other cases should be made carefully. In different situations, some of the work order components might need to be shipped to a fabrication shop before they go to the maintenance site; therefore, they require a different delivery schedule and process. This scenario of the work order components' delivery process was not included in this study. A similar study, perhaps undertaken within a different industry sector, would go some way to provide an objective verification of the findings. This research is also limited as the processes are configured under a SAP system and application to other systems used by maintenance or warehouse operation may be difficult.

Another limitation of the research was that the artefact was not fully implemented; the new process was designed, and this design was the artefact. Thus, the new process was not working during the evaluation step; therefore, caution should be used when interpreting the evaluation results. The evaluation survey is measuring respondents' opinions about the proposed process and not the actual performance of the process after implementation.

\section{Future Research}

This research can be extended in two main ways, through the completion of the design research cycle and through extension to include other elements of the maintenance-logistics processes. The evaluation in this research used a survey to evaluate the opinions held by respondents about how the proposed process would improve operations. Therefore, it does not evaluate the real performance of the suggested process. This represents an initial phase of a larger design science project which will involve the updating of processes in the workplace. Thus, the current study can be improved through completing this design science cycle and conducting summative evaluations of effectiveness of the changes.

This research studied the situations where all the work order components are delivered to a centralised staging area and then dispatched to the workshop. The scope did not include the delivery of components directly from an external supplier or stocker distributor to the workshop, or the processes relating to emergency and urgent work order execution. Only the normal maintenance work order process was studied in this research.

\section{ACKNOWLEDGEMENT}

The authors gratefully acknowledge the assistance and input provided by Abdul Ghamdi.

\section{AUTHOR BIOGRAPHIES}

Dr. Johan vd Westhuizen is a Senior Lecturer of the Department of Logistics at Vaal University of Technology in Vanderbijlpark, South Africa. Dr vd Westhuizen interests are in the areas of strategic management, leadership and entrepreneurship. He is a member of SAIMS (South African Institute of Management Scientists).

Dr. Martin West is Head of the Department of Quality and Operations Management Hamdan Bin Mohammed Smart University in Dubai UAE. Prior to his current position, he was Associate Professor in Logistics and Supply Chain 
Management at Curtin University, in Perth, Australia, director at Deloitte and Manager at Woodside Energy. Dr West focuses on applied research in the areas of supply chain, process improvement, quality and innovation. He is a fellow of the Chartered Institute of Logistics and Transport and is listed in the Who's Who in Supply Chains in Asia.

\section{REFERENCES}

Berente, N., Vandenbosch, B. \& Aubert, B. 2009. Information flows and business process integration. Business Process Management Journal, Vol. 15, No. 1, pp. 119-141.

Bititci, U., Turner, T., Mackay, D., Kearney, D., Parung, J. \& Walters, D. 2007. Managing synergy in collaborative enterprises. Production Planning \& Control, Vol. 18, No. 6, pp. 454-465.

Craighead, C. W., Hanna, J. B., Gibson, B. J. \& Meredith, J. R. 2007. Research approaches in logistics: Trends and alternative future directions. The International Journal of Logistics Management, Vol. 18, No. 1, pp. 22-40.

de Koster, R., Le-Duc, T. \& Roodbergen, K. J. 2007. Design and control of warehouse order picking: A literature review. European Journal of Operational Research, Vol. 182, No. 2, pp. 481-501.

Ellinger, A. E. 2000. Improving marketing/logistics cross-functional collaboration in the supply chain. Industrial Marketing Management, Vol. 29, No. 1, pp. 85-96.

Gable, G. G. 1994. Integrating case study and survey research methods: An example in information systems. European Journal of Information Systems, Vol. 3, No. 2, pp. 112-126.

Galliers, R. D. 1991. Choosing appropriate information systems research approaches: A revised taxonomy. In: NISSEN, H.-E., KLEIN, H. K. \& HIRSCHHEIM, R. (eds.) Information systems research: Contemporary approaches \& emergent traditions. Proceedings of the IFIP TC8/WG 8.2 Working Conference on the Information Systems Research Arena of the 90's Challenges, Perceptions, and Alternative Approaches, Copenhagen, Denmark, 14-16 December 1990. The Netherlands: Elsevier Science Publishers.

Garg, A. \& Deshmukh, S. G. 2006. Maintenance management: Literature review and directions. Journal of Quality in Maintenance Engineering, Vol. 12, No. 3, pp. 205-238.

Gimenez, C. \& Ventura, E. 2005. Logistics-production, logistics-marketing and external integration: Their impact on performance. International Journal of Operations \& Production Management, Vol. 25, No. 1, pp. 20-38.

Giménez, C. \& Ventura, E. 2003. Supply chain management as a competitive advantage in the Spanish grocery sector. International Journal of Logistics Management, Vol. 14, No. 1, pp. 77-88.

Gu, J., Goetschalckx, M. \& McGinnis, L. F. 2007. Research on warehouse operation: A comprehensive review. European Journal of Operational Research, Vol. 177, No. 1, pp. 1-21.

Guenov, M. \& Raeside, R. 1992. Zone shapes in class based storage and multicommand order picking when storage/retrieval machines are used. European Journal of Operational Research, Vol. 58, No. 1, pp. 37-47.

Hevner, A. R., March, S. T., Park, J. \& Ram, S. 2004. Design science in information systems research. MIS Quarterly, Vol. 28, No. 1, pp. 75-105.

Hompel, M. \& Schmidt, T. 2007. Warehouse management automation and organisation of warehouse and order picking systems, Berlin, Heidelberg, Springer-Verlag.

Kutucuoglu, K. Y., Hamali, J., Sharp, J. M. \& Irani, Z. 2002. Enabling BPR in maintenance through a performance measurement system framework. Flexible Services and Manufacturing Journal, Vol. 14, No. 1, pp. 33-52.

Larson, T. N., March, H. \& Kusiak, A. 1997. A heuristic approach to warehouse layout with class-based storage. IIE transactions, Vol. 29, No. 4, pp. 337-348.

Laurel, B. 2003. Design research: Methods and perspectives, Cambridge, MA, MIT Press.

Mahmood, W. H. W., Rahman, M. N. A., Deros, B. M. \& Mazli, H. 2011. Maintenance management system for upstream operations in oil and gas industry: a case study. International Journal of Industrial and Systems Engineering, Vol. 9, No. 3, pp. 317-329.

March, S. T. \& Smith, G. F. 1995. Design and natural science research on information technology. Decision Support Systems, Vol. 15, No. 4, pp. 251-266.

Márquez, A. C., de León, P. M., Fernández, J. F. G., Márquez, C. P. \& Campos, M. L. 2009. The maintenance management framework: A practical view to maintenance management. Journal of Quality in Maintenance Engineering, Vol. 15, No. 2, pp. 167-178.

Marquez, A. C. \& Gupta, J. N. D. 2006. Contemporary maintenance management: Process, framework and supporting pillars. Omega, Vol. 34, No. 3, pp. 313-326.

Näslund, D. 2002. Logistics needs qualitative research - Especially action research. International Journal of Physical Distribution \& Logistics Management, Vol. 32, No. 5, pp. 321 - 338.

Neuman, W. L. 2006. Social research methods: qualitative and quantitative approaches, Boston, MA, Pearson/Allyn and Bacon.

Pagell, M. 2004. Understanding the factors that enable and inhibit the integration of operations, purchasing and logistics. Journal of Operations Management, Vol. 22, No. 5, pp. 459-487.

Palmer, R. D. 1999. Maintenance planning and scheduling handbook, New York, McGraw-Hill. 
Petersen, C. G. \& Aase, G. 2004. A comparison of picking, storage, and routing policies in manual order picking. International Journal of Production Economics, Vol. 92, No. 1, pp. 11-19.

Petersen, C. G., II 1997. An evaluation of order picking routeing policies. International Journal of Operations \& Production Management, Vol. 17, No. 11, pp. 1098.

Petersen, C. G., II 1999. The impact of routing and storage policies on warehouse efficiency. International Journal of Operations \& Production Management, Vol. 19, No. 10, pp. 1053-1064.

Petersen, C. G., II \& Schmenner, R. W. 1999. An evaluation of routing and volume-based storage policies in an order picking operation. Decision Sciences, Vol. 30, No. 2, pp. 481-501.

Rim, S.-C. \& Park, I.-S. 2008. Order picking plan to maximize the order fill rate. Computers \& Industrial Engineering, Vol. 55, No. 3, pp. 557-566.

Rouwenhorst, B., Reuter, B., Stockrahm, V., van Houtum, G. J., Mantel, R. J. \& Zijm, W. H. M. 2000. Warehouse design and control: Framework and literature review. European Journal of Operational Research, Vol. 122, No. 3, pp. 515-533.

Rubin, H. J. \& Rubin, I. S. 2005. Qualitative interviewing: The art of hearing data, Thousand Oaks, CA, Sage.

Söderholm, P., Holmgren, M. \& Klefsjö, B. 2007. A process view of maintenance and its stakeholders. Journal of Quality in Maintenance Engineering, Vol. 13, No. 1, pp. 19-32.

Tompkins, J. A., White, J. A., Bozer, Y. A. \& Tanchoco, J. M. A. 2003. Facilities Planning, New York, NY, Wiley.

Vaishnavi, V. \& Kuechler, W. 2004. Design research in information systems [Online]. Available: http://ais.affiniscape.com/displaycommon.cfm?an=1\&subarticlenbr=279 [Accessed April 2012].

van Hoek, R., Ellinger, A. E. \& Johnson, M. 2008. Great divides: Internal alignment between logistics and peer functions. International Journal of Logistics Management, Vol. 19, No. 2, pp. 110-129.

Venable, J., Pries-Heje, J. \& Baskerville, R. 2012. A comprehensive framework for evaluation in Design Science Research. Seventh International Conference on Design Science Research in Information Systems and Technology. Las Vegas, NV.

Venable, J. R. Year. The role of theory and theorizing in Design Science research. In: CHATTERJEE, S. \& HEVNER, A., eds. First International Conference on Design Science Research in Information Systems and Technology, 2006 Claremont, CA. Claremont Graduate University, 1-18.

Walls, J. G., Widmeyer, G. R. \& El Sawy, O. A. 1992. Building an information system design theory for vigilant EIS. Information Systems Research, Vol. 3, No. 1, pp. 36-59.

Wireman, T. 2008. Maintenance work management processes, New York, Industrial Press Inc.

Yin, R. K. 2009. Case study research: Design and methods, Thousand Oaks, Sage. 